\title{
Cochlear inner hair cells: Effects of transient asphyxia on intracellular potentials
}

\author{
M. Christian Brown, Alfred L. Nuttall, Robert I. Masta and \\ Merle Lawrence \\ Kresge Hearing Research Institute, University of Michigan Medical School, 1301 E. Ann St, Ann Arbor, \\ MI 48109, U.S.A.
}

(Received 11 June 1982; accepted 18 August 1982)

Intracellular potentials were recorded from inner hair cells in the guinea pig cochlea. Transient asphyxia was induced by interrupting respiration for brief periods. Asphyxia caused a hyperpolarization of the resting membrane potential (resting $E_{\mathrm{m}}$ ). The hyperpolarization averaged $2.9 \mathrm{mV}$ for $30 \mathrm{~s}$ asphyxias and $5.7 \mathrm{mV}$ for $45 \mathrm{~s}$ asphyxias. The membrane potential recovered quickly after normal ventilation was resumed. Asphyxia also induced a rapid and profound decrease of the d.c. receptor potential in response to moderate intensity tone bursts at the characteristic frequency of the inner hair cell. At maximal depression, the receptor potential was reduced about $60 \%$ for a $30 \mathrm{~s}$ asphyxia and $100 \%$ for a $45 \mathrm{~s}$ asphyxia. The receptor potential recovered slowly after normal ventilation was resumed. A similar percent reduction and time course of recovery were observed for the a.c. receptor potential.

In recordings from the same animals, the round window compound action potential (CAP) was as severely depressed by asphyxia as the hair cell receptor potentials. The time course of recovery for the CAP was similar to the slow recovery of the d.c. receptor potential. In contrast, the round window cochlear microphonics (CM) and the endolymphatic potential (EP) were affected less by asphyxia and recovered quickly after ventilation was resumed.

Frequency tuning curves (FTCs) for the d.c. receptor potential were measured during the period of maximal receptor potential depression. These FTCs showed decreased tip sensitivity and a decrease in sharpness of tuning, as measured by the $Q_{10}$. These changes were fully reversible. Low frequency (tail) segments of the FTCs were much less affected by asphyxia. The inner hair cell FTC changes during asphyxia were compared with neural FTC changes reported by other investigators. The similarities lead us to the conclusion that the inner hair cell and the auditory neural response to sound are equally sensitive to asphyxia.

Key words: hair cell; asphyxia; Davis theory; hypoxia; frequency selectivity; anoxia.

\section{Introduction}

One popular method for studying inner ear function is to induce cochlear pathology. A number of studies have demonstrated changes in eighth nerve responses using cochlear insults such as aminoglycoside antibiotics [5,14], cyanide and 
furosemide poisoning [11], hypoxia [10], and asphyxia [20]. The latter two studies have emphasized the high susceptibility of auditory neurons to conditions which impair normal metabolism. In these cases, the neural response to sound becomes less sensitive and less sharply tuned.

It has been known for some time that asphyxia affects the round window cochlear microphonics (CM) less than the compound action potential (CAP) $[1,6,12,17]$. This has led to the belief that cochlear hair cells are less sensitive to asphyxia than auditory neurons. Recent techniques developed by Russell and Sellick [21,22] allow intracellular recording from individual inner hair cells. One important result of their work was the demonstration that inner hair cells are as frequency selective as auditory neurons. This result might suggest that changes at the hair cell level could cause at least some of the alterations shown by auditory neurons during conditions of impaired metabolism. We tested this hypothesis by inducing transient asphyxia during recordings from cochlear inner hair cells.

\section{Methods}

Experiments were carried out on a vibration isolation table in a sound- and electrically-shielded booth. Albino guinea pigs with body weights between 200 and $350 \mathrm{~g}$ were anesthetized with freshly prepared sodium pentobarbital $(15 \mathrm{mg} / \mathrm{kg}$ i.p.) and Innovar (fentanyl and droperidol, Pitman-Moore) $(0.4 \mathrm{ml} / \mathrm{kg}$ i.m. $)$. The animals were paralyzed with curare $(0.3 \mathrm{mg})$ and were artificially ventilated. End-respiratory $\mathrm{CO}_{2}$ and heart rate were monitored. A heating blanket maintained the rectal temperature at approximately $38^{\circ} \mathrm{C}$. In some cases, round window temperature was measured with a thermocouple and kept at $38^{\circ} \mathrm{C}$ with heat supplied by several light sources. The cochlea was exposed by a ventral-postauricular surgical dissection and a small fenestra was made into scala tympani of the basal tum mustly according to the method of Sellick and Russell [22]. However, the round window membrane was left intact and perilymph was drained from scala tympani by suction through a hypodermic needle placed at the edge of the fenestra. Perilymph was drained several times just after the fenestra was made, in order to control bleeding from vessels in the otic capsule, but was allowed to refill scala tympani for the remainder of the experiment. A $2 \mathrm{~mm}$ length of 28 gauge silver wire was placed on the otic capsule on the spiral ligament side of the fenestra. This altered the meniscus of perilymph in the fenestra so the basilar membrane became visible, and allowed positioning of the microelectrode with a normal perilymph level in scala tympani. Recordings were obtained only from cochleas which showed unchanged CAP thresholds $(16-20 \mathrm{kHz})$ after the fenestra was made.

Potentials at the round window were measured with a wire electrode. A silver-silver chloride ground wire was placed in the neck muscles. CM was measured with a wave analyzer as a root-mean-square voltage and the CAP amplitude was measured from baseline to the first negative deflection $\left(\mathrm{N}_{1}\right)$. Glass micropipettes for intracellular recordings were filled with a mixture of $2 \mathrm{M}$ potassium chloride and $2 \mathrm{M}$ potassium acetate. Electrodes were beveled using the thick slurry beveling 
technique [15]. A hydraulic microdrive and a piezoelectric pusher were used to advance the electrodes. Electrode signals were amplified by a capacity-compensated d.c. preamplifier and recorded on chart paper and magnetic tape. A voltage-controlled wave analyzer was used to record the a.c. receptor potential. A cell was classified as an inner hair cell at the time of recording by: (1) the visually observed placement and the depth of penetration of the electrode into the organ of Corti, (2) the small resting membrane potential $\left(E_{\mathrm{m}}\right)$ of not more negative than $-45 \mathrm{mV}$, and (3) the large increase in d.c. receptor potential in response to a tone burst, as the electrode penetrated the cell $[13,21]$.

Sound stimuli were produced by a $1 / 2$-inch condenser microphone system compensated for distortion and frequency response. A plastic speculum coupled the sound source to the external auditory meatus to form a closed acoustic system. Sound pressures were measured with a reference $1 / 2$-inch microphone fitted with a calibrated probe tube. Sound pressure levels (SPLs) are given in $\mathrm{dB}$ referenced to $20 \times 10^{-6} \mathrm{~Pa}\left(1 \mathrm{~Pa}=1 \mathrm{~N} / \mathrm{m}^{2}\right)$. Continuous tones were used to produce $\mathrm{CM}$. Tone bursts with a $1 \mathrm{~ms}$ rise-fall time were used to produce the CAP and tone bursts with a $15 \mathrm{~ms}$ rise-fall time and $90 \mathrm{~ms}$ duration were used to evoke the hair cell receptor potentials.

In a typical experiment, the various electrical potentials were recorded during successive asphyxias. First, an inner hair cell was impaled and the a.c. and d.c. receptor potentials [21] and resting $E_{\mathrm{m}}$ were measured during the same asphyxia. At selected intervals during the asphyxic period, an automated system presented tone bursts of various frequencies and intensities which evoked the receptor potentials used to construct frequency tuning curves (FTCs). This procedure took about $18 \mathrm{~s}$ of stimulus presentations. Immediately after loss of the hair cell, the round window $\mathrm{CM}$ and CAP were recorded during other asphyxias of similar length. Later in the experiment, a microelectrode was pushed through the organ of Corti into scala media and the endolymphatic potential (EP) was recorded during another asphyxia.

FTCs for the d.c. receptor potential were calculated by the following procedure. At each frequency, intensity functions were plotted as the logarithm of the d.c. receptor potential against the SPL. The SPL necessary to produce a receptor potential of $2 \mathrm{mV}$ was calculated. This SPL, referred to as the ' $2 \mathrm{mV}$ criterion SPL', was plotted against frequency to form the FTC.

\section{Results}

\section{A comparison of the cochlear potentials during asphyxia}

Fig. 1 shows results obtained from one guinea pig for $45 \mathrm{~s}$ asphyxias. Asphyxia induced reversible changes in all measured cochlear potentials. For comparison purposes, the same sound frequency and intensity were used for the evoked potentials. The EP was reduced from its normal $86 \mathrm{mV}$ to a minimum value of 59 $\mathrm{mV}$ (30\% reduction) and then began a rapid recovery within $10 \mathrm{~s}$ after normal ventilation was resumed. The round window $C M$ was reduced maximally by $49 \%$ and began to recover within $10 \mathrm{~s}$. The inner hair cell resting $E_{\mathrm{m}}$ showed a $6.5 \mathrm{mV}$ hyperpolarization and a rapid recovery. 


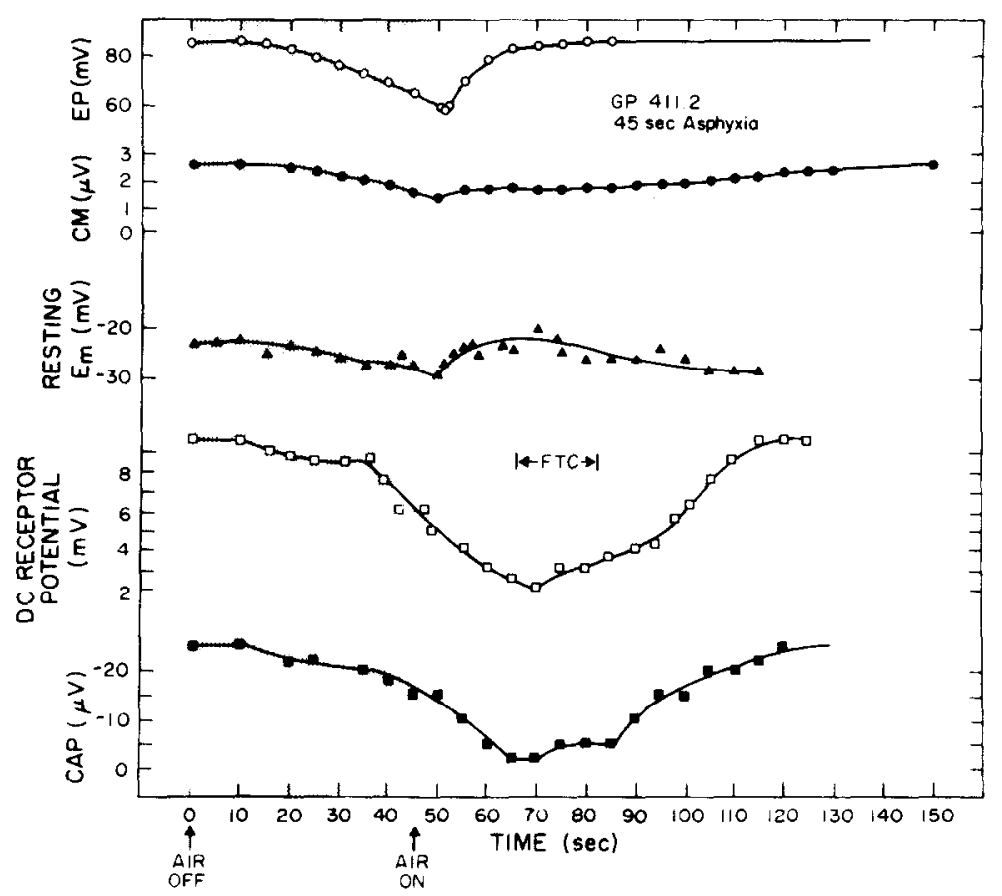

Fig. 1. Cochlear potentials during and after $45 \mathrm{~s}$ asphyxias. Ventilation was stopped during the period indicated by shading. The resting $E_{\mathrm{m}}$ and d.c. receptor potentials were measured during the same asphyxia. EP, CM and CAP were measured during other asphyxias later in the experiment. The CM, d.c. and a.c. receptor potentials, and the CAP were evoked by sounds of $61 \mathrm{~dB}$ SPI at the inner hair cell characteristic frequency $(18 \mathrm{kHz})$. The d.c. receptor potential FTC obtained during the indicated period is shown in Fig. 4 (dotted line).

In contrast, the d.c. receptor potential, evoked by tone bursts at the hair cell characteristic frequency, was reduced from $9.5 \mathrm{mV}$ to $2.0 \mathrm{mV}$ (79\% reduction) and recovered slowly after normal ventilation was resumed. The CAP was reduced maximally by $92 \%$ and showed a slow recovery. These potentials did not return to normal until after $120 \mathrm{~s}$, which was $75 \mathrm{~s}$ after normal ventilation had been resumed. We never observed polarity reversals of the d.c. receptor potential during any of the asphyxias.

Fig. 2 shows results from another guinea pig for $30 \mathrm{~s}$ asphyxias. The EP was reduced 19\% and then began a rapid recovery $7 \mathrm{~s}$ after ventilation was resumed. The hair cell resting membrane potential showed a $2 \mathrm{mV}$ hyperpolarization. These two potentials followed quite similar time courses during asphyxia.

In order to compare the behavior of the cochlear potentials during asphyxia, we computed percent reductions, using the value of the potential at the point of maximal depression and the value before asphyxia. Note from Fig. 1 that the points of maximal reduction do not always occur at the same time for the various cochlear potentials. Fig. 3A shows the average percent reductions for the guinea pigs used in 


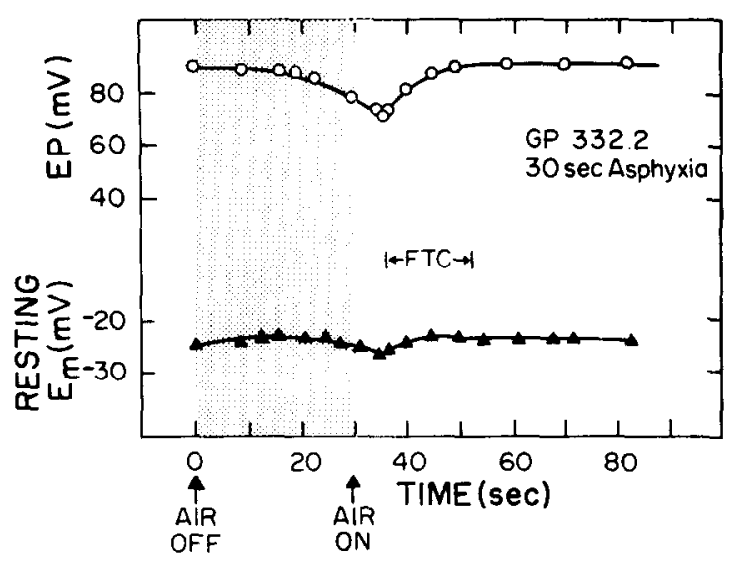

Fig. 2. EP and resting $E_{\mathrm{m}}$ during and after $30 \mathrm{~s}$ asphyxias. Ventilation was stopped during the shaded period. The d.c. receptor potential FTC obtained during the indicated period is shown in Fig. 6 (dashed line).
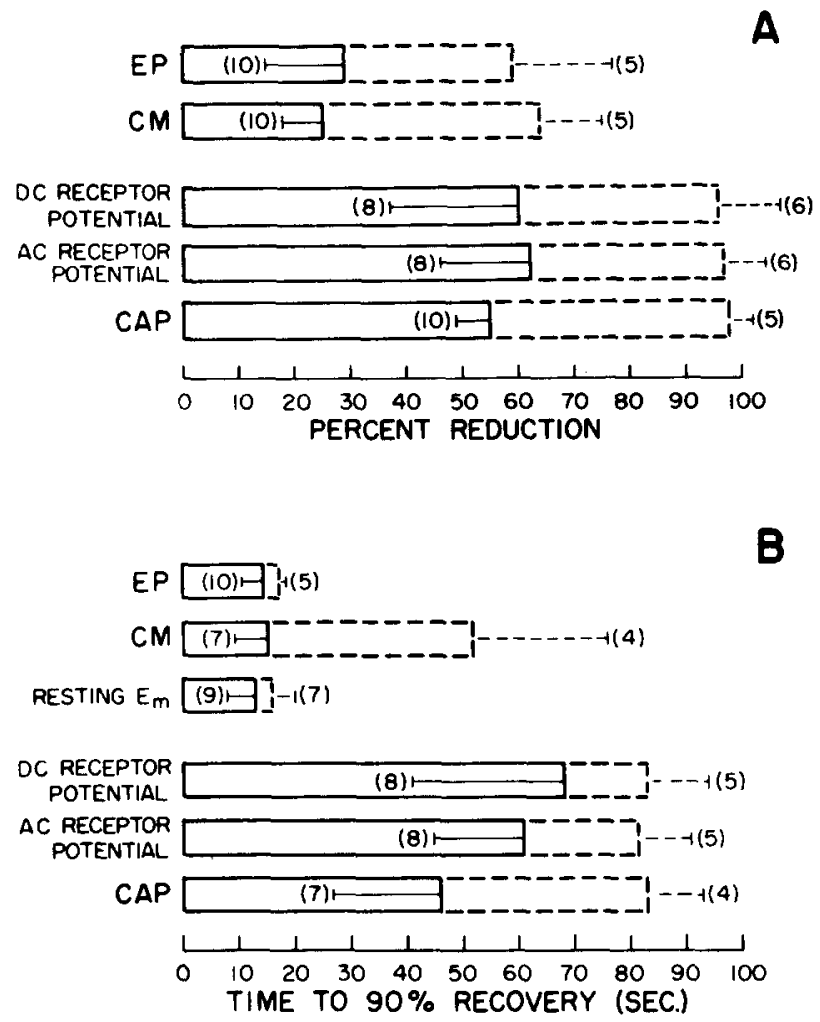

Fig. 3. A. Average cochlear potential percent reductions caused by asphyxia. Percent reduction was calculated using the value at the point of maximal depression and the value before asphyxia. $B$. Average times to $90 \%$ recovery after ventilation was resumed. In both $\mathrm{A}$ and $\mathrm{B}$, solid bars indicate $30 \mathrm{~s}$ asphyxias and dotted bars indicate $45 \mathrm{~s}$ asphyxias. Standard deviations are shown by extensions and numerals indicate the number of observations. The CM, receptor potentials and CAP were evoked by sounds of 61 dB SPL with frequencies between 16 and $20 \mathrm{kHz}$. In each case, sound frequency was set equal to the characteristic frequency of the hair cell. 
this experiment. Solid bars show results for $30 \mathrm{~s}$ asphyxias and dashed bars show results for $45 \mathrm{~s}$ asphyxias. EP and CM showed similar percent reductions for $30 \mathrm{~s}$ asphyxias, as well as for $45 \mathrm{~s}$ asphyxias. The d.c. and a.c. receptor potentials and the CAP were reduced to a greater extent. These three potentials showed quite similar percent reductions for $30 \mathrm{~s}$ asphyxias, as well as for $45 \mathrm{~s}$ asphyxias. Percent reductions were not calculated for resting $E_{\mathrm{m}}$ hyperpolarizations. For $30 \mathrm{~s}$ asphyxias, the average hyperpolarization was $2.9 \pm 2.7 \mathrm{mV}$ for 13 hair cells, and for $45 \mathrm{~s}$ asphyxias the average was $5.7 \pm 3.4 \mathrm{mV}$ for 9 hair cells. The largest hyperpolarization observed for a $45 \mathrm{~s}$ asphyxia was $10.5 \mathrm{mV}$.

We also made a general comparison of the time to $90 \%$ recovery, shown in Fig. 3B. For the $30 \mathrm{~s}$ case, EP and CM once again behaved similarly. For $45 \mathrm{~s}$ asphyxias, $\mathrm{CM}$ and EP usually began recovery at the same time but the CM recovery occurred over an extended period (see Fig. 1) and hence had a longer time to $90 \%$ recovery. The hair cell resting $E_{\mathrm{m}}$ and the EP always showed very similar recovery times. In contrast, the d.c. and a.c. receptor potentials and the CAP took much longer to recover from asphyxia. These three potentials showed very similar recovery times.

\section{Inner hair cell FTC changes during asphyxia}

In recordings from eight inner hair cells, FTCs for the d.c. receptor potential were recorded before, during, and after $30 \mathrm{~s}$ asphyxias. In addition, recordings from five of these hair cells were also obtained during $45 \mathrm{~s}$ asphyxias. The degree of frequency selectivity of FTCs was measured by the ' $Q_{10}$ ', defined as the characteristic frequency divided by the bandwidth of the FTC at $10 \mathrm{~dB}$ above the characteristic frequency criterion SPL. The characteristic frequency is the sound frequency to which the hair cell is most sensitive at the SPL which evokes a $2 \mathrm{mV}$ receptor potential. For the eight FTCs before asphyxia, $Q_{10}$ values ranged from 6.03 to $16.2(\mathrm{Av} .=8.9$ ).

Fig. 4 presents FTCs from one inner hair cell for normal conditions and during $30 \mathrm{~s}$ and $45 \mathrm{~s}$ asphyxias (see figure legend for the experimental protocol). For this guinea pig, the time courses of the cochlear potentials for $45 \mathrm{~s}$ asphyxias were shown in Fig. 1. The asphyxic FTCs were taken during the time interval when the hair cell receptor potentials were maximally depressed. The most salient FTC changes occurred in the finely-tuned, low threshold 'tip' of the FTC. At the characteristic frequency, the $30 \mathrm{~s}$ asphyxia (dashed line) raised the $2 \mathrm{mV}$ criterion SPL by $17 \mathrm{~dB}$ and had less effect on the low frequency tail segment of the FTC. For the $45 \mathrm{~s}$ asphyxia (dotted line), there was complete loss of the tip section of the FTC. Hypersensitivity was shown in the tail section, although this was a rare finding. The normal $Q_{10}$ of 8 was reduced to 4.5 for the $30 \mathrm{~s}$ asphyxia and to 1.8 during the $45 \mathrm{~s}$ case. Thus, the loss in tip sensitivity was accompanied by a decrease in sharpness of tuning. The solid circles in the figure show the FTC completely recovered from asphyxia.

Fig. 5 shows the effects of 30 and $45 \mathrm{~s}$ asphyxias on the FTC from another hair cell. As in the previous case, the most obvious result was the loss of the sharply tuned, low SPL segment of the FTC. However, in this case larger tip sensitivity decreases were seen and there was some reduction in sensitivity of the tail section of the tuning curve. The normal $Q_{10}$ of 16.2 was reduced to 4.2 for the $30 \mathrm{~s}$ asphyxia 


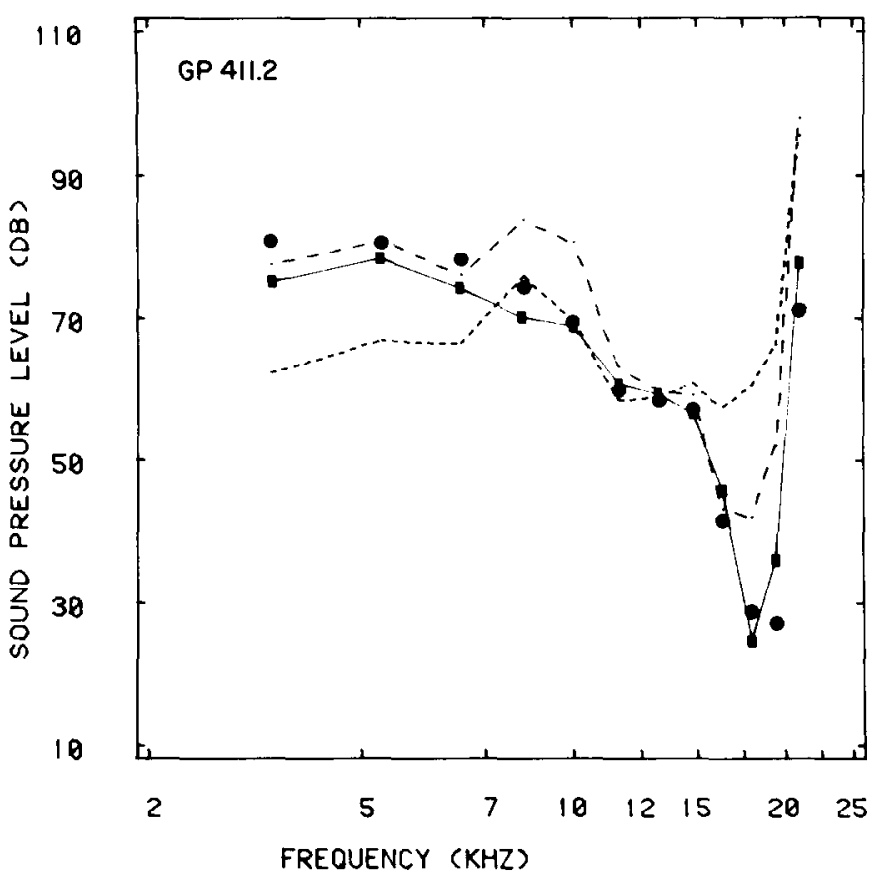

Fig. 4. d.c. receptor potential FTCs for 30 and $45 \mathrm{~s}$ asphyxias. A $2 \mathrm{mV}$ criterion was used in all cases. The normal FTC taken at the beginning of the experiment is shown - $)$. Then, ventilation was stopped for $30 \mathrm{~s}$ and another FTC ( $-\ldots)$ was taken at the point of maximal receptor potential depression (between 32 and $54 \mathrm{~s}$ after the air-off time). Another FTC (not plotted) taken between 108 and $136 \mathrm{~s}$ showed full recovery. Following recovery, a $45 \mathrm{~s}$ asphyxia was induced. The time course for the hair cell potentials during this second asphyxia was shown in Fig. 1. An FTC taken during the asphyxic period indicated in Fig. 1 is shown (--..-.). Later, a final FTC $(\bullet \bullet)$ was taken between 147 and $165 \mathrm{~s}$ from the $45 \mathrm{~s}$ air-off time.

and to 1.2 for the $45 \mathrm{~s}$ asphyxia. Because the tip segment for the $30 \mathrm{~s}$ asphyxia FTC extends less than $10 \mathrm{~dB}$, the $Q_{10}$ was based on an extrapolated tip segment [4]. This extrapolation procedure was necessary only for this FTC. As seen in Fig. 5, this hair cell fully recovered from asphyxia.

Fig. 6 shows the effects of a $30 \mathrm{~s}$ asphyxia on the FTC from a third inner hair cell. For this guinea pig, the time courses for two cochlear potentials during $30 \mathrm{~s}$ asphyxias were plotted in Fig. 2. The asphyxic FTC shown in Fig. 6 was taken during the period indicated in Fig. 2.

For $30 \mathrm{~s}$ asphyxias, the average $Q_{10}$ percent reductions for the d.c. receptor potential FTCs were $45 \pm 14 \%$ for 8 hair cells and for $45 \mathrm{~s}$ asphyxias were $78 \pm 12 \%$ for 5 hair cells. A detailed analysis of the changes in tuning for the a.c. receptor potential was not undertaken. Fig. 7 summarizes the changes induced by asphyxia, plotting the d.c. receptor potential $Q_{10}$ against the $2 \mathrm{mV}$ criterion SPL at the characteristic frequency. Dashed lines connect normal to $30 \mathrm{~s}$ asphyxia points; dotted lines connect normal to $45 \mathrm{~s}$ asphyxia points. In all cases studied, criterion 


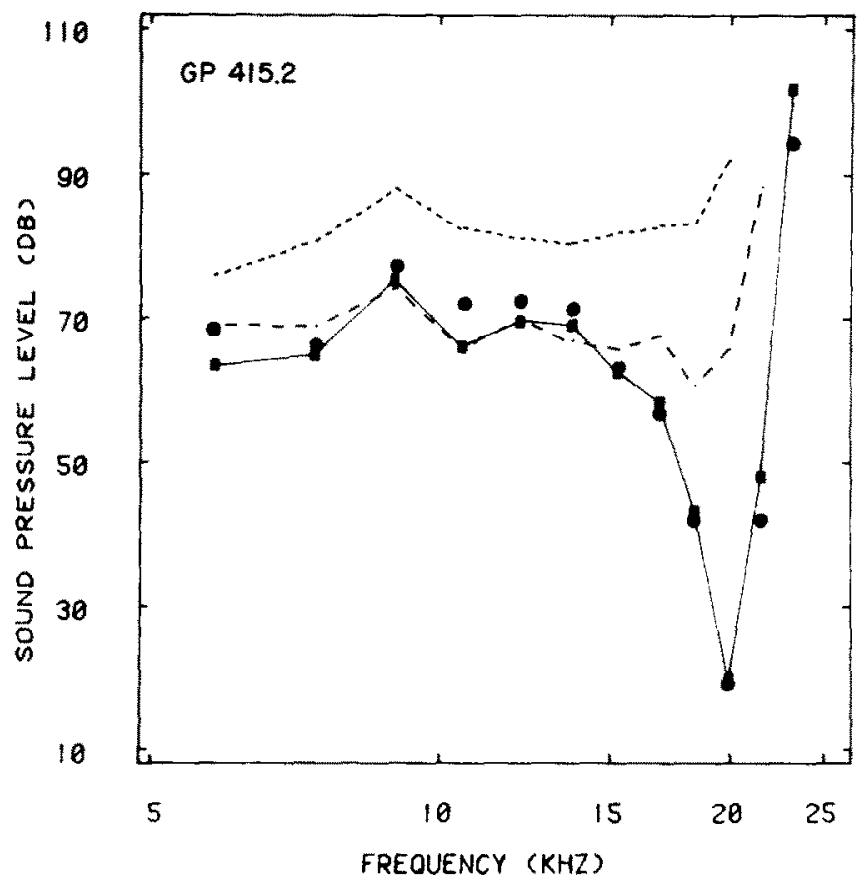

Fig. 5. d.c. receptor potential FTCs for normal conditions, 30 and $45 \mathrm{~s}$ asphyxias. Experimental protocol as in Fig. 4. e_- normal; - - - $30 \mathrm{~s}$ asphyxia, taken between 58 and $77 \mathrm{~s} ;-\ldots, 45 \mathrm{~s}$ asphyxia taken between 60 and $78 \mathrm{~s}$. The recovered FTC $(\bullet)$ was obtained between 166 and $184 \mathrm{~s}$ after the $45 \mathrm{~s}$ air-off time.

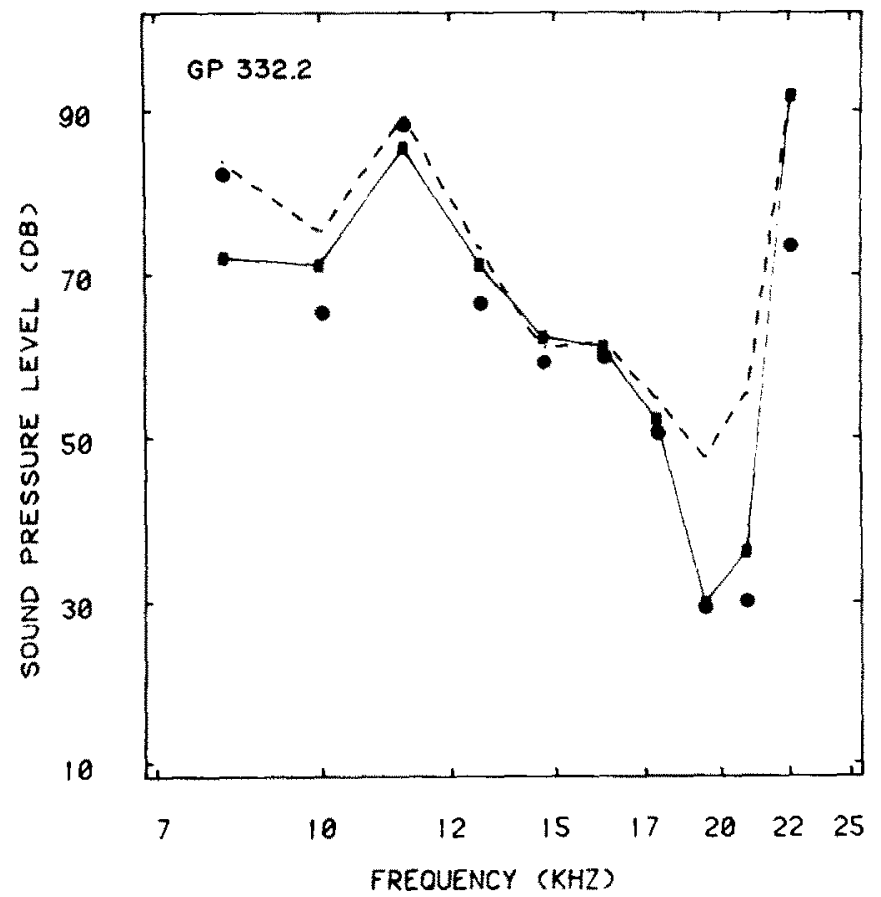

Fig. 6. d.c. receptor potential FTCs for a $30 \mathrm{~s}$ asphyxia, for the same inner hair cell as in Fig. 2. - n normal; _ _ - $30 \mathrm{~s}$ asphyxia, taken between 37 and $54 \mathrm{~s} ; \bullet$, recovered, taken between 93 and $110 \mathrm{~s}$. 


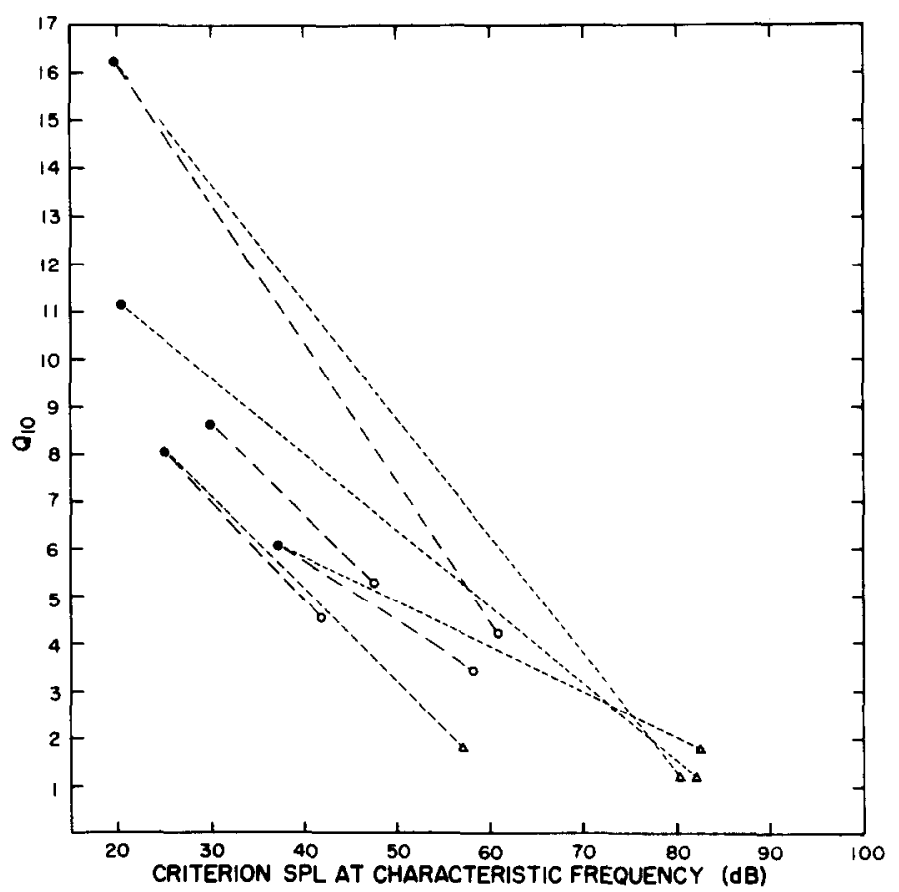

Fig. 7. Effects of asphyxia on the $Q_{10}$ and the $2 \mathrm{mV}$ criterion SPL at the characteristic frequency. The normal values (๑) are connected to the values for $30 \mathrm{~s}$ asphyxias (-- $)$ ) and in some cases for $45 \mathrm{~s}$ asphyxias $(---\Delta)$. All cases showed fully reversible changes.

SPL at the characteristic frequency recovered to within $10 \mathrm{~dB}$ of its pre-asphyxia value.

\section{Intensity function changes during asphyxia}

We also noted changes in intensity functions for the d.c. receptor potential during $30 \mathrm{~s}$ asphyxias. One example for a $30 \mathrm{~s}$ asphyxia is shown in Fig. 8, for the same inner hair cell used in Figs. 2 and 6. In general, large effects were seen for intensity functions near the characteristic frequency, whereas intensity functions for frequencies about one octave below were less affected. The alterations usually occurred for the low SPL portion; however, in some characteristic frequency intensity functions, the high SPL portion of the function was affected. In these cases, the d.c. receptor potential at saturation was below the normal level or the asphyxic function did not saturate within the range of SPLs used.

Lack of influence of resting $\mathrm{E}_{m}$ on changes induced by asphyxia

Several previous intracellular studies have reported difficulty in holding organ of Corti cells for long periods of time $[3,21,24]$. During our recordings, hair cells with $E_{\mathrm{m}}$ values between -25 and $-40 \mathrm{mV}$ were impaled. Subsequently, over the course of several seconds, the resting $E_{\mathrm{m}}$ often decreased to a less negative value and held at 


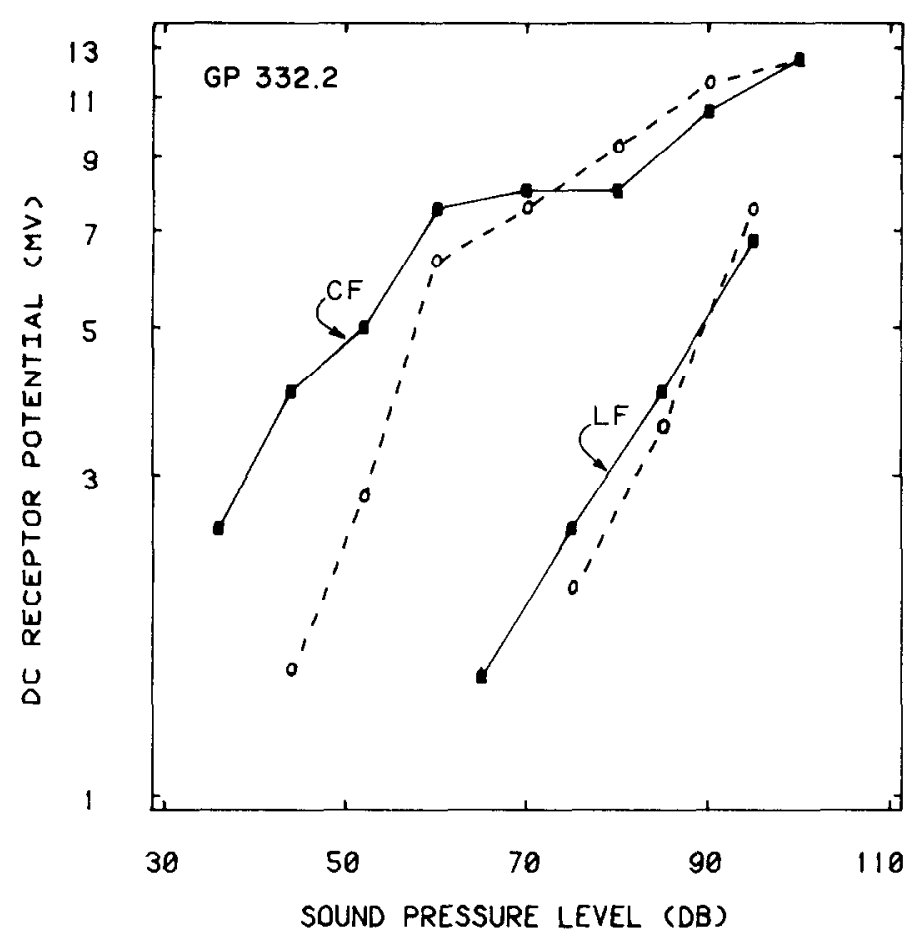

Fig. 8. Intensity functions for the d.c. receptor potential. Functions are shown for a sound frequency equal to the hair cell characteristic frequency $(\mathrm{CF}=19.5 \mathrm{kHz})$ and for a low frequency $(\mathrm{LF}=10 \mathrm{kHz})$. Normal (- - and asphyxic $(\mathrm{O} \ldots \mathrm{O})$ functions are shown. This recording was from the same hair cell shown in Figs. 2 and 6.

this value for several minutes until an abrupt loss of the membrane potential occurred. We wondered whether resting $E_{\mathrm{m}}$ correlated with the magnitude of the changes induced by asphyxia. The effect of including cells with varying resting $E_{\mathrm{m}}$ values was examined graphically and by computing correlation coefficients. Three groups were considered: $30 \mathrm{~s}$ asphyxias, $45 \mathrm{~s}$ asphyxias, and all asphyxias lumped together. For the combined group of 22 asphyxias, hair cell final resting $E_{\mathrm{m}}$ values ranged from -11 to $-30 \mathrm{mV}$. For each of the three groups, the resting $E_{\mathrm{m}}$ was graphed against the amount of membrane hyperpolarization induced by asphyxia. No obvious pattern was evident. For the two variables of resting $E_{\mathrm{m}}$ and amount of hyperpolarization, in each of the three groups, Pearson product-moment correlation coefficients were calculated. Two-tailed $t$-tests, at the $5 \%$ significance level, allowed us to accept the hypothesis of zero correlation. A similar procedure was carried out for examining the effects of the resting $E_{\mathrm{m}}$ on the percent reduction in $Q_{10}$ caused by asphyxia. For the three groups (with a combined group of 13 asphyxias), no obvious graphical relationship existed, and calculated correlation coefficients were within limits necessary to accept the hypothesis of zero correlation. Thus, over the range of 
resting $E_{\mathrm{m}}$ values considered, the amount of membrane hyperpolarization and the percent reduction in $Q_{10}$ induced by asphyxia were independent of the resting $E_{\mathrm{m}}$.

\section{Discussion}

Intracellular recordings from the organ of Corti have revealed a difference in resting $E_{\mathrm{m}}$ between inner hair cells and other cell types [13,19,21]. Inner hair cells have a resting $E_{\mathrm{m}}$ not more negative than $-45 \mathrm{mV}$, whereas other cell types have much more negative membrane potentials, reaching up to $-90 \mathrm{mV}$. Nuttall and Lawrence [18] explored the effects of asphyxia on the resting $E_{\mathrm{m}}$ of cells within the organ of Corti. From the highly negative average resting $E_{\mathrm{m}}$ of $-83 \mathrm{mV}$ and the small standard deviation, it seems unlikely that inner hair cells were included within the sample. In contrast to the hyperpolarizations of inner hair cells shown in the present study, Nuttall and Lawrence [18] reported either depolarization or no change in membrane potentials, even during longer asphyxias.

The inner hair cell hyperpolarizations are consistent with the Davis theory [7] of cochlear hair cell function. This theory holds that a standing current from scala media into the hair cells is driven by the electrochemical potential of the endolymph linked in series with the electrochemical potential within the hair cells. We know that asphyxia depresses the EP and lowers the driving force for this hypothesized current. If the standing current keeps the inner hair cells depolarized, asphyxia could cause hyperpolarization by decreasing the standing current. This is supported by the very similar recovery time courses for the EP and the resting $E_{\mathrm{m}}$. At the present time however, we cannot rule out a more direct action of asphyxia, such as a short-term change in a hair cell membrane resistance, resulting in a hyperpolarization.

The inner hair cell hyperpolarizations during asphyxia may result in changes at the auditory neuron. The release of chemical transmitter from the hair cell is often assumed to be proportional to the hair cell membrane potential and, according to one theory [16], spontaneous firing in the auditory neuron results from a spontaneous release of transmitter from the hair cell. A depolarization of the hair cell, caused by sound, would result in an increase of chemical transmitter released and an increase in neural firing. A hyperpolarization of the hair cell, caused by asphyxia, would result in a decrease in transmitter released and a decrease in neural activity (a decrease in spontaneous firing). Decreases in spontaneous discharge of auditory neurons have been observed with asphyxia [16] and with hypoxia [9].

In agreement with previous reports [13,21], we observed that d.c. receptor potential FTCs recorded from inner hair cells can be as sharply tuned as FTCs from auditory neurons [8], when the degree of tuning is measured by the $Q_{10}$. In order to compare visually the inner hair cell FTC changes during asphyxia with auditory neuron FTC changes, we have re-plotted a tuning curve from a study by Robertson and Manley [20] (Fig. 9). Their experimental preparation is similar to the guinea pig basal turn preparation used in the present study, except that recordings were made from the spiral ganglion. These authors reduced the ventilation rate in order to cause partial asphyxia. The asphyxic neural data in Fig. 9, showing complete loss of the tip 


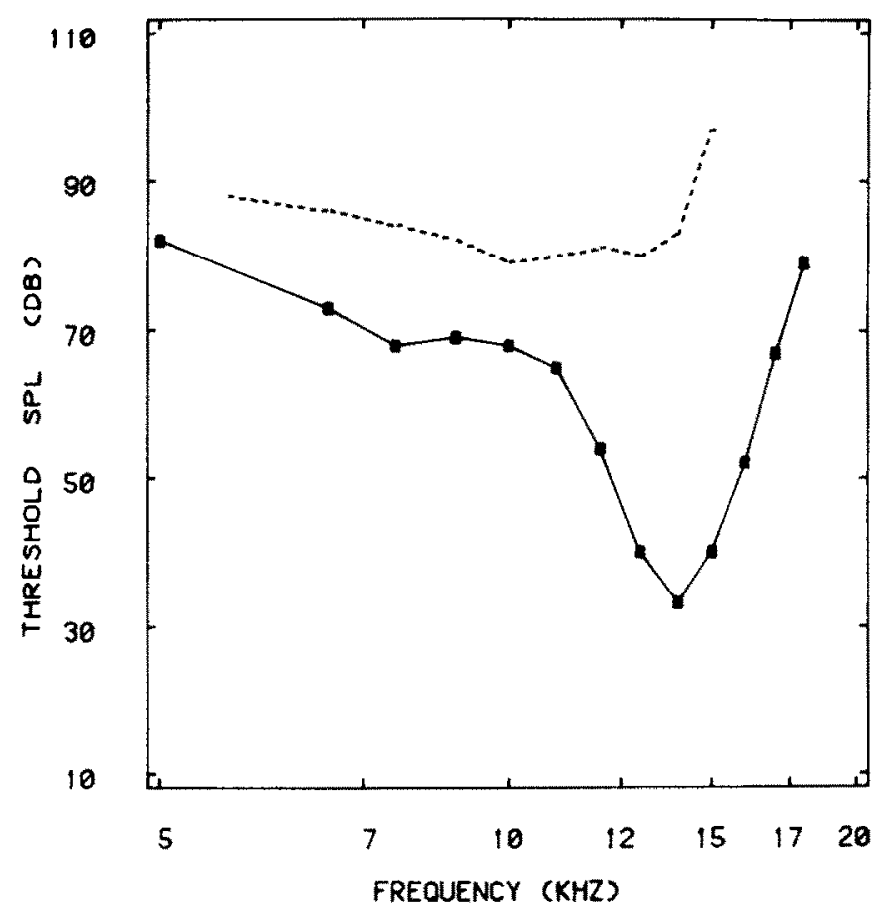

Fig. 9. Effects of asphyxia on an auditory neuron FTC (from [20]). Threshold SPL represents the SPL at which the neuron slightly responds to sound. Asphyxia was induced by slowing the ventilation rate. Normal (1- - and asphyxic (-..--) cases are shown.

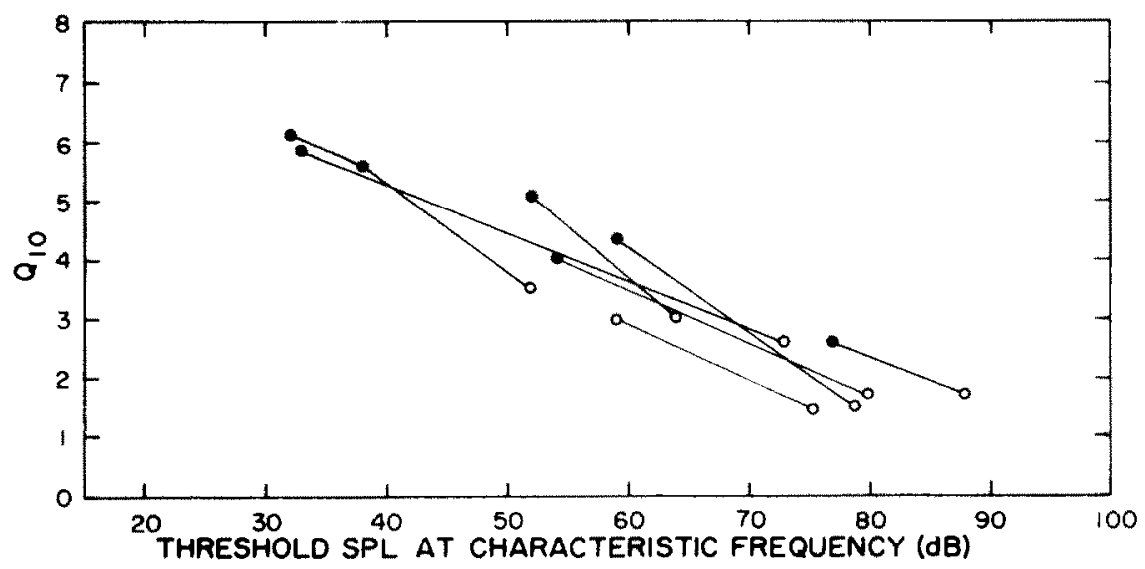

Fig. 10. Effects of asphyxia on auditory neural $Q_{10}$ and the threshold SPL at the characteristic frequency (from [20]). The normal values ( $\bullet$ ) are connected to the asphyxic values $(O)$ by solid lines. Most cells showed fully reversible changes. 
segment and less influence in the tail, are quite similar to most cases of the inner hair cell data. In both, changes are fully reversible. Evans [10] has shown, at least in cat auditory nerve fibers, that these changes can result from hypoxia alone.

In Fig. 10, we have re-plotted other neural data from Robertson and Manley [20]. This figure shows the 'linear' relationship of decrease in $Q_{10}$ which always accompanied an increase in threshold SPL at the characteristic frequency. A similar dependence was found (Fig. 7) for inner hair cell FTCs taken at the point of maximal receptor potential depression.

Russell and Sellick [21] have demonstrated similarities in the shape of intensity functions for inner hair cells and for auditory neurons. In their results for hair cells, the ordinate was plotted as the logarithm of the receptor potential, whereas for neurons, the ordinate is usually plotted as a linear spike rate. Receptor potentials seem to have no lower limit or 'threshold', whereas the lowest neural discharge rate is limited by the spontaneous rate. Evans [10] has shown that for auditory neurons, hypoxia depressed the intensity functions for frequencies near the characteristic frequency to a greater extent than the intensity functions for low frequencies. The saturation discharge rate appeared to be the same for the normal and hypoxic cases. Our results suggest that asphyxia can alter the intensity function for the inner hair cell d.c. receptor potential in a similar manner. However, in some asphyxic cases the saturation d.c. receptor potential was lower than in the normal case.

To these neural and hair cell similarities during asphyxia, we add the measurements of percent depression and recovery times for the receptor potentials and CAP within the same animals. In all cases, a close correspondence was observed between the inner hair cell receptor potentials and the CAP. We thus conclude that the electrophysiological changes shown by auditory neurons during asphyxia result from corresponding electrophysiological changes in inner hair cells.

Finally, we note the similarity in shape of the asphyxic FTCs reported in this study with guinea pig basilar membrane isovelocity curves taken post mortem [23]. Whether the short-term changes induced by asphyxia exist at the level of basilar membrane motion is a matter for future study.

\section{Acknowledgements}

This work was supported by Program Project Grant NS-05785, and Research Grants NS-15107 and NS-11731, and Training Grant NS-07106. A preliminary report of this research has been presented [2]. We wish to thank Dr. N.Y.-S. Kiang for his suggestion of the term 'asphyxia' as an appropriate description of respiratory cessation.

\section{References}

1 Bornschein, H. and Gernandt, B. (1950): Selective removal of the nerve discharge component from the cochlear potential during anoxia. Acta Physiol. Scand. 21: 82-95. 
2 Brown, M.C., Nuttall, A.L., Masta, R.I. and Lawrence, M. (1981): Effects of short-term anoxia on the intracellular potentials from cochlear inner hair cells. Society for Neuroscience, 11 th Annual Meeting Abstracts 7: 535 .

3 Dallos, P. (1968): On the negative potential within the organ of Corti. J. Acoust. Soc. Am. 44: $818-819$.

4 Dallos, P. and Harris, D. (1978): Properties of auditory nerve responses in absence of outer hair cells. J. Neurophysiol. 41:365-383.

5 Dallos, P., Ryan, A., Harris, D., McGee, T. and Ozdamar, O. (1977): Cochlear frequency selectivity in the presence of hair cell damage. In: Psychophysics and Physiology of Hearing, pp. 249-261. Editors: E.F. Evans and J.P. Wilson. Academic Press, London.

6 Davis, H., Fernandez, C. and McAuliffe, D.R. (1950): The excitatory process in the cochlea. Proc. Natl. Acad. Sci. 36: 580-587.

7 Davis, H. (1965): A model for transducer action in the cochlea. Cold Spring Harbor Symp. Quant. Biol. 30: $181-190$.

8 Evans, E.F. (1972): The frequency response and other properties of single fibres in the guinea-pig cochlear nerve. J. Physiol. (London) 226: 263-287.

9 Evans, E.F. (1974): Auditory frequency selectivity and the cochlear nerve. In: Facts and Models in Hearing, Communication and Cybernetics 8, pp. 118-131. Editors: E. Zwicker and E. Terhardt. Springer-Verlag, New York.

10 Evans, E.F. (1974): The effects of hypoxia on the tuning of single cochlear nerve fibres. J. Physiol. (London) 238: 65P-67P.

11 Evans, E.F. and Klinke, R. (1974): Reversible effects of cyanide and furosemide on the tuning of single cochlear nerve fibers. J. Physiol. (London) 242: $129 \mathrm{P}$.

12 Fernandez, C. and Alzate, R. (1959) Modifications of cochlear responses by oxygen deprivation. Arch. Otolaryngol. 69: 82-94.

13 Goodman, D.A. and Smith, R.L. (1981): Cochlear inner hair cells: intracellular responses and staining. Association for Research in Otolaryngology, Abstracts of the IVth Midwinter Research Meeting.

14 Harrison, R.V. and Evans, E.F. (1977): The effects of hair cell loss (restricted to outer hair cells) on the threshold and tuning properties of cochlear fibers in the guinea pig. In: INSERM, Vol. 68, pp. 105-124. Editors: M. Portmann and J.-M. Aran.

15 Lederer, W.J., Spindler, A.J. and Eisner, D.A. (1979): Thick slurry bevelling: a new technique for beveling extremely fine microelectrodes and micropipettes. Pflügers Arch. 381: 287-288

16 Manley, G.A. and Robertson, D.R. (1976): Analysis of spontaneous activity of auditory neurons in the spiral ganglion of the guinea pig cochlea. J. Physiol. (London) 255: 323-336.

17 Misrahy, G.A., Shinabarger, E.W. and Arnold, J.E. (1958): Changes in cochlear endolymphatic oxygen availability, action potential, and microphonics during and following asphyxia, hypoxia, and exposure to loud sounds. J. Acoust. Soc. Am 30: 701-704.

18 Nuttall, A.L. and Lawrence, M. (1979): Intracellular potential changes of Corti's organ with anoxia. Arch. Otolaryngol. 105: 574-578.

19 Nuttall, A.L., Brown, M.C., Masta, R.I. and Lawrence, M. (1981): Inner hair cell responses to the velocity of basilar membrane motion in the guinea pig. Brain Res. 211: 171-174.

20 Robertson, D. and Manley, G.A. (1974): Manipulation of frequency analysis in the cochlear ganglion of the guinea pig. J. Comp. Physiol. 91: 363-375.

21 Russell, I.J. and Sellick, P.M. (1978): Intracellular studies of hair cells in the mammalian cochlea. J. Physiol. 284: 261290.

22 Sellick, P.M. and Russell, I.J. (1979): Intracellular studies of the receptor potentials of inner hair cells of the guinea pig cochlea: techniques. In: Auditory Investigation: The Scientific and Technological Basis, pp. 368-381. Editor: H.A. Beagley. Oxford Press, Oxford.

23 Sellick, P.M., Patuzzi, R. and Johnstone, B.M. (1982): Measurement of basilar membrane motion in the guinea pig using the Mössbauer technique. J. Acoust. Soc. Am. 72, 131-141.

24 Sohmer, H.S., Peake, W.T. and Weiss, T.F. (1971): Intracochlear potential recorded with micropipets: I. Correlations with micropipet location. J. Acoust. Soc. Am. 50: 572-586. 